\title{
A Simulation of Reserve Book Activities in a College Library Using GPSS/360
}

\begin{abstract}
The reserve book activities of a typical college library were analyzed by means of a computer simulation. Service levels were determined for various combinations of reserve book stocks and class sizes. Of particular importance was the relationship between reserve book utilization and service levels provided. The computer model contained behavioral assumptions as to the student population served. The model also allowed library policy decisions to be examined.
\end{abstract}

M ODERN MANAGEMENT TECHNIQUES are being applied in almost every administrative setting. Libraries are no exception, and the results of research in the areas of mathematical model building, operations analysis, and computer applications are increasingly being applied to library activities. This paper describes the use of such techniques to analyze reserve book activity in a simulated college library. Through the use of GPSS/ 360 (an advanced simulation language), a computer model of reserve book operations in a college library was developed. This appears to be a worthwhile area to investigate by means of computer simulation, because library administrators obviously wish to limit their in-

J. V. Baumler is associate professor, College of Administrative Science, The Ohio State University, Columbus. J. L. Baumler is former staff librarian, Belmont Memorial Library, Belmont, Massachusetts. The authors acknowledge their thanks to the Instructional and Research Computer Center at the Ohio State University for providing computer time in support of the research reported here. vestment in multiple copies of reserve books while at the same time providing adequate service to their patrons. Results of the simulation provide an understanding of the factors affecting service levels in reserve book operations.

\section{THE MOdeL}

The computer model represented a portion of a college library. This library was open from 8:00 a.m. until midnight, a total of sixteen hours daily. The policy of the reserve desk activities simulated was that books were provided to students on a first-come, first-served basis. If the book was not available, the student could have his or her name put on a waiting list. Further, no reserve books were checked out within thirty minutes of closing time.

There were three key features of the computer simulation model. First, it allowed a wide range of parameter values to be used. For instance, the number of students expected per day was set at 30 , then 75 , and finally 300 to represent three different patron groups. For each of these three patron groups, three dif- 
ferent reading assignments were simulated, one at a time. A very short assignment required only ten minutes for the average student; a longer assignment averaged thirty minutes; and a third assignment averaged one hour. Finally, for each of these nine combinations of patron group size and length of reading assignment, six different quantities of books on reserve were represented. Thus a total of fifty-four different combinations of parameter values allowed the representation of wide variations in group sizes, reading assignment lengths, and the number of books on reserve.

The second basic feature relates to the behavioral assumptions about students embodied in the model. The model represents students as (1) having different reading speeds, (2) being heavier users of the library at certain times of the day (afternoon and evening) than at others (morning); and (3) having personal time constraints, hence being reluctant to join long queues to obtain a book and growing increasingly impatient while waiting for a book.

The third key feature of the model is that it incorporates library policies. The major policy tested was the impact of a one-hour limit on reserve books. The longest reading assignment, which required more than one hour for many of the students, was simulated two ways, with and without a one-hour policy limit.

\section{Results}

Two measures of service were used. The most obvious such measure is the portion of the patron group which was able to obtain the reserve book sought. To illustrate: with a daily demand of seventy-five students, a reading assignment requiring thirty minutes for the average student (some taking more time, some less), and five copies of the book on reserve, a service level of 98.2
TABLE 1

Results of Simulation: Reading Assignment of Ten Minutes

\begin{tabular}{ccrr}
\hline \hline $\begin{array}{c}\text { Size of } \\
\text { Patron Group }\end{array}$ & $\begin{array}{c}\text { Number of } \\
\text { Reserve } \\
\text { Books }\end{array}$ & $\begin{array}{r}\text { Percent } \\
\text { Served }\end{array}$ & $\begin{array}{r}\text { Percent Served } \\
\text { without Delay }\end{array}$ \\
\hline 30 & 1 & 99.2 & 70.6 \\
30 & 2 & 100.0 & 94.4 \\
30 & 3 & 100.0 & 98.4 \\
30 & 4 & 100.0 & 100.0 \\
75 & 1 & 85.1 & 20.3 \\
75 & 3 & 100.0 & 92.6 \\
75 & 5 & 100.0 & 100.0 \\
75 & 8 & 100.0 & 100.0 \\
300 & 1 & 33.3 & .4 \\
300 & 5 & 95.8 & 68.1 \\
300 & 10 & 100.0 & 99.0 \\
300 & 20 & 100.0 & 100.0 \\
\hline
\end{tabular}

percent was obtained. That is, almost all of the seventy-five students would be able to obtain the book, and the library could be reasonably satisfied with the level of service provided.

However, a second measure of the level of service was also used. That was the percent of each patron group who obtained the reserve book without delay. The model contained a queue for students to join if the supply of reserve books was exhausted. It should be recalled that student behavior in the model depicted impatient students, reluctant to join long queues. For example, no student would wait for a book if he or she would be more than tenth in line, and there was only a fifty-fifty chance that the student would wait if he or she were to be fifth in line. As midnight approached, the closing time of the library, he or she was even less likely to join a long queue. The model represented a reserve desk operation which strictly maintained a first-come, first-served policy. In the illustration above, five books were almost sufficient to serve the patron group fully. But in terms of service without delay, only 76.4 percent of the patron group was so fortunate. It would require eight books to provide virtually complete service without delay for seventy-five stu- 
TABLE 2

Results of Simulation: Reading AssignMent of Thirty Minutes

\begin{tabular}{ccrr}
\hline \hline $\begin{array}{c}\text { Size of } \\
\text { Patron Group }\end{array}$ & $\begin{array}{c}\text { Number of } \\
\text { Reserve } \\
\text { Books }\end{array}$ & $\begin{array}{r}\text { Percent } \\
\text { Served }\end{array}$ & $\begin{array}{c}\text { Percent Served } \\
\text { without Delay }\end{array}$ \\
\hline 30 & 1 & 77.7 & 29.3 \\
30 & 2 & 99.2 & 69.8 \\
30 & 3 & 100.0 & 89.7 \\
30 & 4 & 100.0 & 96.2 \\
75 & 1 & 39.0 & 3.2 \\
75 & 3 & 86.2 & 35.0 \\
75 & 5 & 98.2 & 76.4 \\
75 & 8 & 100.0 & 99.3 \\
300 & 1 & 11.0 & 0.3 \\
300 & 5 & 52.7 & 5.6 \\
300 & 10 & 85.5 & 41.7 \\
300 & 20 & 99.7 & 97.8 \\
\hline
\end{tabular}

dents a day if the reading assignment averaged thirty minutes. Tables 1 through 3 present the two performance measures-percent served and percent served without delay-for the various combinations of parameters simulated (patron group size, length of reading assignment, and number of books on reserve).

One of the striking results evident in these tables is the added expense involved in providing a high level of service in terms of service without delay rather than just in terms of complete service with delay for some students. In the illustration discussed above, five books were adequate to allow virtually all students to fulfill their reserve book reading assignment, but eight books, or a 60 percent increase, were required to provide virtually total service without delay. As a broad generalization, the full data in Tables 1 through 3 also suggest that to move from virtually complete service with some waiting to virtually complete service without delay would, in general, require about a 60 percent increase in reserve books. This represents a rather sizable investment, a fact which administrators setting service level objectives should keep in mind.

While the results in Tables 1 through
TABLE 3

Results of Simulation: Reading Assignment of Sixty Minutes

\begin{tabular}{ccrc}
\hline \hline $\begin{array}{c}\text { Size of } \\
\text { Patron Group }\end{array}$ & $\begin{array}{c}\text { Number of } \\
\text { Reserve } \\
\text { Books }\end{array}$ & $\begin{array}{r}\text { Percent } \\
\text { Served }\end{array}$ & $\begin{array}{c}\text { Percent Served } \\
\text { without Delay }\end{array}$ \\
\hline 30 & 1 & 52.3 & 19.8 \\
30 & 2 & 81.0 & 39.6 \\
30 & 3 & 94.5 & 63.4 \\
30 & 4 & 98.3 & 85.0 \\
30 & 5 & 99.2 & 96.0 \\
30 & 6 & 100.0 & 95.2 \\
75 & 1 & 21.6 & 2.0 \\
75 & 3 & 55.0 & 14.1 \\
75 & 5 & 80.2 & 32.3 \\
75 & 8 & 97.5 & 69.0 \\
75 & 10 & 99.3 & 90.6 \\
75 & 15 & 100.0 & 100.0 \\
300 & 1 & 5.6 & .0 \\
300 & 5 & 27.7 & 1.7 \\
300 & 10 & 53.5 & 7.6 \\
300 & 20 & 85.7 & 45.1 \\
300 & 30 & 98.6 & 92.5 \\
300 & 40 & 100.0 & 99.7 \\
\hline
\end{tabular}

3 are of some interest in their own right, the primary task of analysis was to derive generalizations from the data which could possibly apply to reserve book activities elsewhere. One such generalization was discussed above-the 60 percent increase in books required to eliminate delays in service. Another area in which generalizations were sought was the relationship between service levels and reserve book utilization. Fortunately, a regression equation was found which related utilization with service level. The interesting thing about this equation is that it closely fits the data obtained from all the simulations conducted. Thus, there were no significant economies of scale observed in reserve book activities. The relationship between level of service and utilization is largely independent of the size of patron groups, the length of reading assignments, and the number of books on reserve. This being the case, a simple graph (Figure 1) can be constructed to relate reserve book utilization with service level. Since the relationship be- 
Percent of Day

Reserve Books

Are Utilized

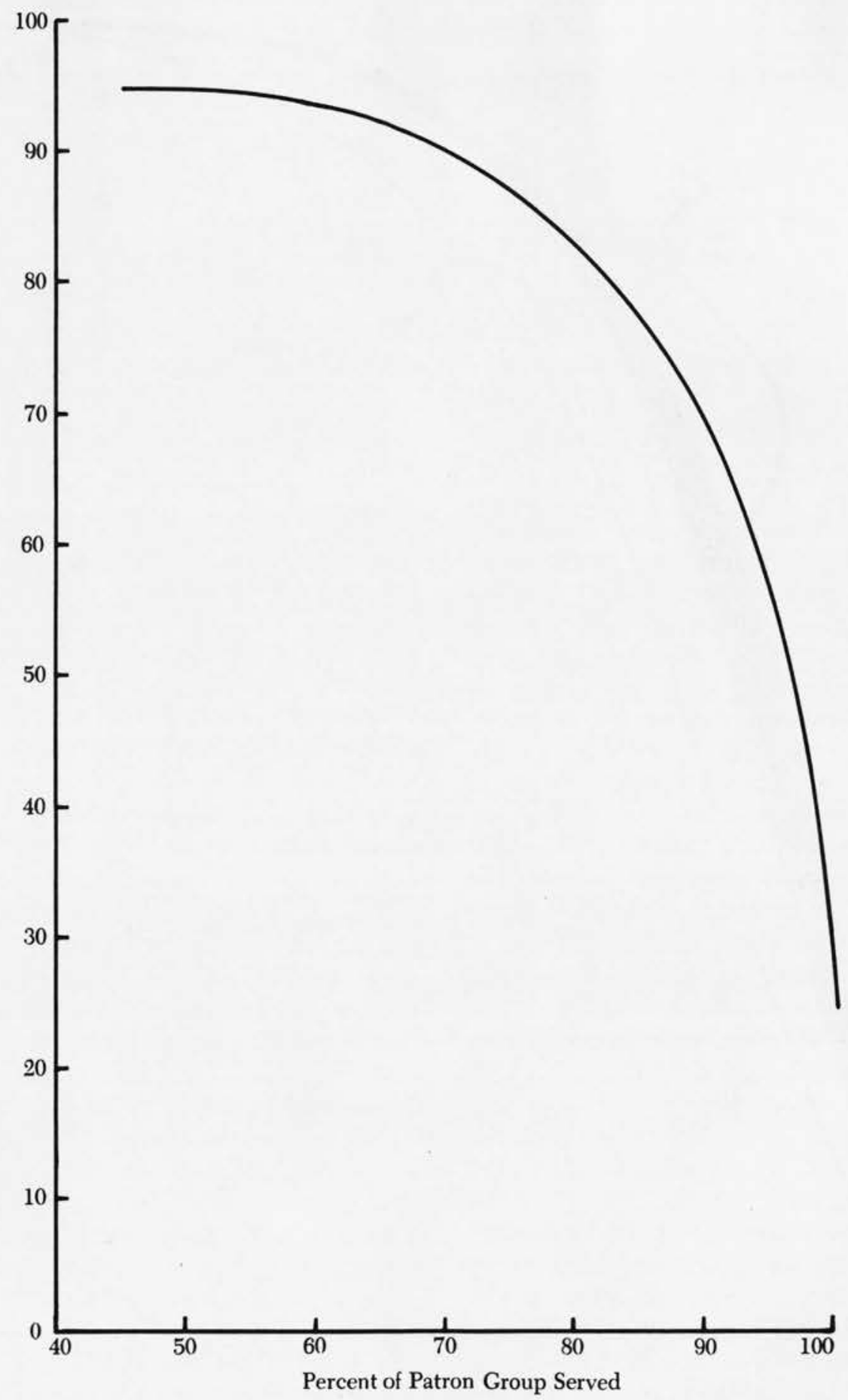

Fig. 1

Utilization of Reserve Books Versus Service Level 


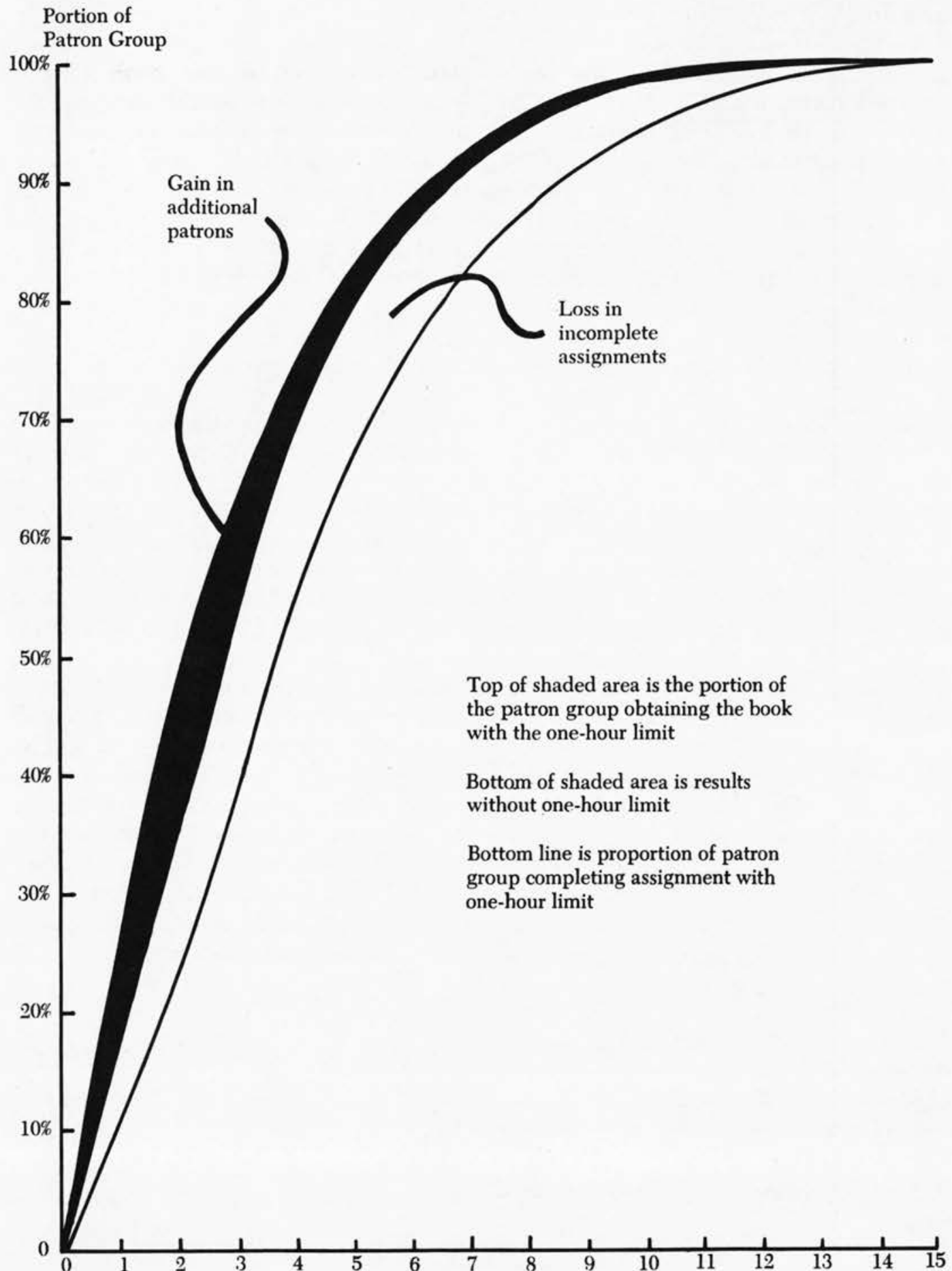

Number of Books on Reserve

Fig. 2

Effect of One-Hour Limitation on Use of Reserve Books: Patron Group of Seventy-five, Reading Assignment Averaging One Hour 
tween percent utilization and service level does not depend upon the number of books on reserve, the size of the patron group, or the length of the reading assignment, Figure 1 is thought to apply to all reserve book operations, at least approximately. One way in which this chart could be used is to investigate a complaint that for a particular title the reserve book supply is inadequate. The librarian may not know the exact size of the patron group using this book or the amount of time each student requires to complete his assigned reading; but the librarian could determine the utilization of this title. If it is found that this book (or set of books) is used 75 percent of the day, use of Figure 1 would indicate that only 87 percent of the patron group is being served.

Figure 1 also indicates the large slack required to provide full service. To serve 95 percent of a patron group, enough books must be on hand that they are no more than 57 percent utilized.

An important part of the simulation was testing the effect of library policies limiting the time for which a reserve book may be held. Consider the following illustration from the data in Table 3. A patron group of seventy-five students will come to the library in a particular day seeking a reserve book of which the library has five copies. The average student will require sixty minutes to complete his assignment, but it may take up to ninety minutes for some students. The library's stock of this book is somewhat inadequate. If each student fortunate enough to obtain a copy of the reserve book keeps it until he or she has finished his reading, only 80.2 percent of the patron group will be served. In such a situation the library could limit use of this book to one hour. Such a step would increase the number of students who obtain access to the book but reduce the number of students completing their reading assignment. In the above illustration, the percent of the patron group obtaining the book increases from 80.2 to 82.9 by imposing the one hour limit, a very modest increase. But such a limit reduces from 80.2 percent to 55.8 percent the portion of the patron group that completes the reading assignment. Figure 2 depicts the gain in those obtaining the book and the loss in fulfillment of reading assignments for a patron group of seventy-five with a reading assignment averaging one hour when a one hour policy limit is imposed. Figure 2 indicates the high price, in terms of incomplete reading, that is paid for the slight increase in exposure to the book. As a broad generalization, data from all three patron groups suggest that a time limit on reserve books results in approximately four students having to turn in the book before completion of their assignment for every additional student this policy allows to obtain access to the book. Hence such policy time limits could be counterproductive.

\section{Conclusion}

Modern management techniques are finding ever-increasing applications in today's library. This research demonstrated how one of these techniques, computer simulation, could be applied. 


\section{WHY CHOOSE FAXON?}

\section{Good Reasons:}

1. A choice of three renewal services to suit your requirements.

2. A choice of six (one, two, and three-year) ordering plans.

3. A common expiration date achieved on subscriptions.

4. A yearly invoice with full periodical information.

5. Annual receipt of the Faxon Librarians' Guide to Periodicals.

6. FACS - Faxon's Automated Claim System with a quarterly follow-up report on all claims activity.

7. Serials Updating Service - a monthly newsletter with the latest information on serials changes and irregularities.

8. Punch cards containing all the data shown on the annual invoice.

9. A toll-free WATS line.

10. An agency that combines small personal handling with large automated know-how.

But these are only 10 of the many reasons for choosing the F. W. Faxon Company. For a full description of our "Total Service Package" - our various services and how they can be useful to you - write for a copy of our Service Brochure and our annual Librarians' Guide to Periodicals. Or call today on our toll-free line.

Library Business is our only Business - since 1881.

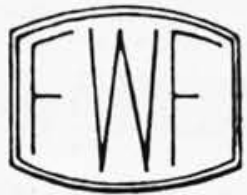

\section{F.W. faXON COMPANY, InC.}

Library Magazine Subscription Agency

15 SOUTHWEST PARK. WESTWOOD, MASS. 02090

Tel: 800-225-7894 (toll-free) • 617-329-3350 (collect in Mass. and Canada only) 